\title{
Métodos de Plantio de Gliricídia (Gliricidia sepium (Jacq.) Walp.) em Estacas para Produção de Forragem
}

\author{
Benedito Marques da Costa ${ }^{1}$, Gean Carlo Soares Capinan ${ }^{2}$, Heloisa Helena Moura dos \\ Santos $^{3}$, Maxuel Alves da Silva ${ }^{4}$
}

\begin{abstract}
RESUMO - Gliricídia, uma leguminosa arbórea utilizada no sombreamento de cacaueiros e na produção de forragem, é comumente empregada como cerca viva, madeira e lenha e pode ser multiplicada por sementes e por frações do caule ou de estacas. Conduziu-se este estudo na Escola de Agronomia da UFBA, em Cruz das Almas - Bahia, com o objetivo de avaliar métodos de plantio por estaquia, a fim de se identificar aquele de maior índice de pegamento das estacas, maior produção de forragem e menor custo de implantação. O delineamento experimental foi em blocos casualizados, com cinco tratamentos e cinco repetições. Os tratamentos foram os seguintes: 1) estacas de $1 \mathrm{~m}$ de comprimento plantadas verticalmente em covas; 2) estacas de 0,5 m de comprimento plantadas verticalmente em covas; 3) estacas de 0,25 m de comprimento plantadas verticalmente em covas; 4) estacas de $1 \mathrm{~m}$ de comprimento plantadas horizontalmente dentro do sulco; 5) estacas de 0,5 m de comprimento plantadas horizontalmente dentro sulco. As estacas de 1,0 m de comprimento plantadas verticalmente dentro de covas (método 1) ou horizontalmente dentro de sulcos (método 4), após 14 dias de colhidas, são os métodos mais recomendáveis por apresentarem menores custos na preparação das estacas e operações de plantio, proporcionando melhores lucros por hectare quando consideradas as receitas das produções de matéria seca.
\end{abstract}

Palavras-chave: custo de implantação, leguminosa arbórea, plantio por estacas, produção de matéria seca

\section{Establishment Methods of Gliricidia (Gliricidia sepium (Jacq.) Walp.) from Stakes for Forage Production}

\begin{abstract}
Gliricidia sepium has been used as shade tree in cocoa plantations, living fences, wood, fuel wood and livestock forage. It can be grown from seeds and from cuttings or stakes. This experiment was carried out to evaluate five grown methods from Gliricidia cuttings in other to identify the one showing highest stake sprouting indexes, forage production and least implantation costs. The experiment was in a randomized block design with five treatments and five replications. The treatments were the followings: 1 ) stakes with $1 \mathrm{~m}$ in length placed vertically in pits; 2) stakes with .5 m in length placed vertically in pits; 3) stakes with . $25 \mathrm{~m}$ in length placed vertically in pits; 4) stakes with $1 \mathrm{~m}$ in length placed horizontally in furrows; 5) stakes with $.5 \mathrm{~m}$ in length placed horizontally in furrows. Stakes with $1 \mathrm{~m}$ in length placed vertically in pits (method 1) or placed horizontally in furrows (method 4), after 14 days from harvesting, are the most recommended methods since they showed the least costs in expending time to prepare the cutting stakes and for planting operations, providing better profits per hectare, when the incomes from dry matter productions are taken into consideration.
\end{abstract}

Key Words: arboreous legume, cost of implantation, dry matter production, planting by stakes

\section{Introdução}

A espécie gliricídia (Gliricidia sepium (Jacq.) Walp.) é uma leguminosa arbórea de uso múltiplo mais cultivada nas regiões tropicais, onde cresce bem e em que a Leucaena leucocephala não alcança desenvolvimento satisfatório (Simons \& Stewart, 1994). Pertence à subfamília Faboideae, de porte médio, apresenta folhas alternadas, imparimpinadas de 15 a $25 \mathrm{~cm}$ de comprimento, ovaladas, elípticas ou lanceoladas, flores vistosas de cor rosa ou matizadas de púrpura, agrupadas em cachos curtos e vagens medindo de 10 a $15 \mathrm{~cm}$ de comprimento por 1,5 cm de largura, com 3 a 8 sementes planas (Quintero de Vallejo, 1993).

Esta espécie é usada para sombreamento de cacaueiros, como cerca viva, como madeira ou lenha e na produção de forragem para alimentação animal (Baggio, 1984).

A forragem de gliricídia é constituída de folhas e hastes tenras e possui na matéria seca $20 \%$ a $30 \%$ de

\footnotetext{
${ }^{1}$ Professor Titular, Departamento de Zootecnia, Escola de Agronomia/UFBA. E.mail: bmarques@ufba.br

2 Acadêmico do curso de graduação em Agronomia da UFBA.

${ }^{3}$ Aluna do curso de mestrado em Ciências Agrárias da UFBA, área de Produção Animal. E.mail: heloisams@fsonline.com.br

${ }^{4}$ Aluno do curso de mestrado em Ciências Agrárias da UFBA, Área de Produção Animal.
} 
proteína bruta, 53\% de FDN, 33\% de FDA e digestibilidade in vitro da matéria seca 54 a $70 \%$ (Galindo et al., 1989; Camero, 1994; Gómez et al., 1995). Contudo, apesar de seu valor nutritivo, animais ruminantes rejeitam inicialmente suas folhas, provavelmente em razão de seu odor, sugerindo que o problema esteja nos compostos voláteis liberados da sua superfície. Segundo Simmons \& Stewart (1994), alguns métodos têm sido usados para melhorar sua palatabilidade, como desidratação, adição de melaço ou sal, além de adaptação dos animais à nova dieta ou seu confinamento junto a outros animais já adaptados ao consumo de gliricídia.

Carew (1983) sugeriu que as folhas de gliricídia poderiam ser usadas como única fonte de proteína para ruminantes. Contudo, Liyanage \& Wijeratne (1987) observaram que novilhas de Sri Lanka recebendo uma mistura (1:1) de Gliricidia sepium/ Brachiaria milliformis apresentaram maiores, ganhos de peso que aquelas alimentadas exclusivamente com gliricídia. Nochebuena \& O’Donovan (1986) relataram que ovinos, no México, apresentaram maior consumo e digestibilidade da matéria seca, quando gliricídia foi usada como suplemento em até 30\% da dieta, juntamente com feno de capim.

Pode ser estabelecida por sementes e por estaquia, no entanto, graças às dificuldades na obtenção de sementes, sua multiplicação tem sido realizada com relativo sucesso utilizando frações do caule ou estacas, com tamanhos de 10 a $20 \mathrm{~cm}$, com 5 a $6 \mathrm{~cm}$ de diâmetro (Contreras et al., 1998); 30 a 50 cm, com $1-2,5 \mathrm{~cm}$ a 6 ou mais cm de diâmetro (Fact, 1998).

Gliricídia é uma espécie de clima tropical que se adapta desde o nível do mar até 1600 metros de altitude em regiões subúmidas e secas, desenvolvendo-se melhor em clima com precipitação anual entre 1500 e $2000 \mathrm{~mm}$ e estação seca definida (Quintero de Vallejo, 1993). Cresce em vários de tipos de solos (desde areias puras até regossolos pedregosos sem estratificação e vertissolos negro profundo), porém tem sido cultivada em solos argilosos até francos arenosos, com pH de 5,5 a 7,0 (Hughes, citado por Parrotta, 1992). Quando implantada em solos pobres de tabuleiros do sul do Estado da Bahia, gliricídia apresenta bom desenvolvimento, com elevadas produções de biomassa (Silva, 2000). Entretanto, vale lembrar que, apesar de a gliricídia vegetar bem em solos poucos férteis, apresenta melhor desempenho naqueles de melhor fertilidade e profundos (Carvalho Filho et al., 1988).

\footnotetext{
R. Bras. Zootec., v.33, n.6, p.1969-1974, 2004 (Supl. 2)
}

Este trabalho foi conduzido com o objetivo de avaliar métodos de plantio por estaquia, utilizando-se diferentes frações do caule, para identificar aquele de menor custo de implantação, de bom índice de pegamento das estacas e de produção de forragem satisfatória.

\section{Material e Métodos}

O experimento foi realizado nas dependências da Escola de Agronomia, Universidade Federal da Bahia, em Cruz das Almas - Bahia, no período de junho de 2001 a março de 2002. O município está situado na região fisiográfica do Recôncavo Baiano e apresenta as coordenadas geográficas de $12^{\circ} 40^{\prime} 19^{\prime \prime}$ latitude sul, $39^{\circ} 06^{\prime} 23^{\prime \prime}$ de longitude oeste de Greenwich e altitude média de $220 \mathrm{~m}$.

O clima, segundo a classificação de Thornthwaite \& Mather, é do tipo subúmido, com pluviosidade média anual de $1170 \mathrm{~mm}$, com variações entre 900 e $1300 \mathrm{~mm}$, sendo os meses de março a agosto os mais chuvosos e de setembro a fevereiro, os mais secos. A temperatura média anual e de $24,1^{\circ} \mathrm{C}$ e o balanço hídrico apresenta evapotranspiração potencial de 1267 mm anuais, havendo excedente hídrico apenas durante os meses de junho, julho e agosto (Ribeiro et al., 1995). Constam, na Tabela 1, os dados climáticos referentes ao período experimental. O solo foi classificado como Latossolo Amarelo Álico Coeso, de textura argilosa e relevo plano (Ribeiro et al., 1995).

Efetuou-se o plantio em área anteriormente ocupada com capim Brachiaria decumbens Stapf., localizada no Setor de Forragicultura do Departamento de Zootecnia. O preparo do solo foi realizado em junho de 2001, mediante aração e gradagem. Em seguida, com base na análise do solo (Tabela 2), aplicou-se calcário dolomítico (850 kg/ha), em cobertura, por ocasião da gradagem e, após 60 dias, adubação manual nos sulcos e nas covas de plantio, utilizando-se superfosfato simples (120 kg/ha de $\left.\mathrm{P}_{2} \mathrm{O}_{5}\right)$ e cloreto de potássio (120 kg/ha de $\mathrm{K}_{2} 0$ ). Posteriormente, realizou-se o plantio das estacas nos sulcos e nas covas, em agosto de 2001, de acordo com os tratamentos experimentais (Tabela 3).

As estacas de gliricídia, com diâmetro médio de $3 \mathrm{~cm}$, obtidas de plantas com mais de quatro anos de idade, provenientes do sítio Santo Antônio, em Santo Amaro - BA, foram mantidas à sombra, por aproximadamente 14 dias, antes de serem plantadas.

O delineamento experimental foi em blocos casualizados, com cinco tratamentos e cinco blocos 
Tabela 1 - Dados climatológicos referentes ao período de junho de 2001 a março de 2002

Table 1 - Climatic data from June 2001 to March 2002

\begin{tabular}{|c|c|c|c|c|}
\hline \multirow[t]{2}{*}{$\begin{array}{l}\text { Meses } \\
\text { Months }\end{array}$} & \multirow[t]{2}{*}{$\begin{array}{l}\text { Pluviosidade }(\mathrm{mm}) \\
\text { Rainfall }\end{array}$} & \multicolumn{2}{|c|}{$\begin{array}{l}\text { Temperaturas médias }\left({ }^{\circ} \mathrm{C}\right) \\
\text { Average temperatures }\left({ }^{\circ} \mathrm{C}\right)\end{array}$} & \multirow[t]{2}{*}{$\begin{array}{c}\text { Umidade relativa (\%) } \\
\text { Relative humidity(\%) }\end{array}$} \\
\hline & & $\begin{array}{l}\text { Mínima } \\
\text { Minimum }\end{array}$ & $\begin{array}{l}\text { Máxima } \\
\text { Maximum }\end{array}$ & \\
\hline Junho (June) & 202,5 & 19,7 & 26,3 & 88 \\
\hline Julho (July) & 170,3 & 18,9 & 26,2 & 86 \\
\hline Agosto (August) & 141,8 & 18,5 & 25,3 & 88 \\
\hline Setembro (September) & 140,2 & 19,2 & 26,9 & 83 \\
\hline Outubro (October) & 98,3 & 20,7 & 28,8 & 81 \\
\hline Novembro (November) & 3,9 & 21,5 & 31,1 & 52 \\
\hline Dezembro (December) & 65,4 & 22,4 & 31,4 & 75 \\
\hline Janeiro (January) & 240,9 & 22,3 & 29,7 & 82 \\
\hline Fevereiro (February) & 88,1 & 22,1 & 30,9 & 76 \\
\hline Março (March) & 87,5 & 22,3 & 31,3 & 53 \\
\hline
\end{tabular}

Fonte: Posto Meteorológico da EMBRAPA/CNPMF/MA - Cruz das Almas - BA.

Tabela 2 - Características químicas do solo da área experimental

Table 2 - Soil chemical characteristics of experimental area

\begin{tabular}{|c|c|c|c|c|c|c|c|c|c|c|}
\hline pH H20 & $\mathrm{P}$ & $\mathrm{K}$ & $\mathrm{Ca}$ & $\mathrm{Mg}$ & $\mathrm{Al}$ & $\mathrm{H}+\mathrm{Al}$ & $\mathrm{Na}$ & $S$ & CTC & $\mathrm{V}$ \\
\hline \multicolumn{7}{|c|}{ ppm-MEHLICH } & & & & \\
\hline 5,3 & 2 & 25 & 0,9 & 0,4 & 0,3 & 2,80 & 0,016 & 1,38 & 4,18 & 33,01 \\
\hline
\end{tabular}

Fonte: Laboratório de Química de Solos e Fertilizantes - Escola de Agronomia/UFBA.

Tabela 3 - Métodos de plantio, tamanho e número de estacas por parcela

Table 3 - Planting methods, length and number of stakes

\begin{tabular}{lcc}
\hline $\begin{array}{l}\text { Métodos de plantio } \\
\text { Planting methods }\end{array}$ & $\begin{array}{c}\text { Tamanho das estacas (m) } \\
\text { Length of stakes }\end{array}$ & $\begin{array}{c}\text { Número de estacas por parcela } \\
\text { Number of stakes per plot }\end{array}$ \\
\hline $\begin{array}{l}\text { - Vertical em covas } \\
1 \text { - Vertical in pits }\end{array}$ & 1,00 & 60 \\
2 - Vertical em covas & 0,50 & 60 \\
2 - Vertical in pits & & 60 \\
3 - Vertical em covas & 0,25 & 30 \\
3 - Vertical in pits & 1,00 & 60 \\
4 - Horizontal em sulcos & & 6 \\
4 - Horizontal in furrows & 0,50 & \\
5 - Horizontal em sulcos & &
\end{tabular}

ou repetições. Os tratamentos foram métodos de plantio de estacas de gliricídia plantadas verticalmente em covas ou horizontalmente em sulcos a aproximadamente $15 \mathrm{~cm}$ de profundidade (Tabela 3).

As parcelas possuíam área de $15 \mathrm{~m}^{2}$, com as dimensões de $3 \mathrm{~m}$ x $5 \mathrm{~m}$, e uma área útil de $3 \mathrm{~m}^{2}$ correspondente às dimensões de $2 \mathrm{~m} \times 3 \mathrm{~m}$. Os espaçamentos de plantio foram os seguintes: a) nos tratamentos 1,2 e 3 , as estacas foram plantadas em covas distanciadas a $0,5 \mathrm{~m}$; b) nos tratamentos 4 e 5 , as estacas foram plantadas em sulcos distanciados de $0,5 \mathrm{~m}$.

O modelo matemático usado no experimento foi o seguinte:

\footnotetext{
R. Bras. Zootec., v.33, n.6, p.1969-1974, 2004 (Supl. 2)
} 


$$
\mathrm{Y}_{\mathrm{ij}}=\mathrm{m}+\mathrm{t}_{\mathrm{i}}+\mathrm{b}_{\mathrm{j}}+\mathrm{e}_{\mathrm{ij}}
$$

em que: $\mathrm{Y}_{\mathrm{ij}}=$ tempo gasto para o preparo das estacas, sulcamento e coveamento, índice de pegamento das estacas, custo de implantação e produção de matéria seca da forragem, referentes ao tratamento i no bloco $\mathrm{j} ; \mathrm{m}=$ média geral; $\mathrm{t}_{\mathrm{i}}=$ efeito do tratamento $\mathrm{i}$, sendo $\mathrm{i}=1,2,3,4,5 ; \mathrm{b}_{\mathrm{j}}=$ efeito do bloco $\mathrm{j}$, sendo $\mathrm{j}=1,23$, 4, 5; $\mathrm{e}_{\mathrm{ij}}=$ erro aleatório associado a cada observação.

$\mathrm{Na}$ análise de variância dos dados, utilizou-se o prorama SAEG (Sistema para Análises Estatísticas) versão 8,0 da Universidade Federal de Viçosa, descrito por Ribeiro Júnior (2001). As comparações ente as médias foram realizadas a $1 \%$ de probabilidade, usando-se o teste Tukey.

Os parâmetros de avaliação do presente estudo foram os seguintes:

1) tempo gasto para o preparo das estacas de cada método de plantio;

2) tempo gasto para sulcamento e coveamento do terreno para o plantio das estacas de Gliricidia;

3) índice de pegamento das estacas (IPE), aos 60 dias após o plantio;

4) podução média de matéria seca das folhas, em um corte, realizado aos 210 dias após o plantio a uma altura média de $30 \mathrm{~cm}$ do chão;

5) custo de implantação da leguminosa em cada método de plantio.

O índice de pegamento das estacas (IPE) foi calculado por intermédio da seguinte fórmula:

Número de estacas pegadas na parcela IPE $(\%)=$ x 100

Número de estacas plantadas na parcela

\section{Resultados e Discussão}

Nos métodos de plantio 1, 2, 3 e 5, foram plantadas 60 estacas de gliricídia por parcela, enquanto, no método 4, apenas 30 (Tabela 3). O tempo gasto na preparação das estacas de plantio diferiu significativamente entre tratamentos $(\mathrm{P}<0,01)$ pelo teste $\mathrm{F}$, observando-se o menor tempo na preparação das estacas no método 4 (18 minutos) e o maior no 3 (55 minutos) (Tabela 4). O tempo de 55 minutos foi gasto na preparação de 60 estacas com tamanhos individuais de 0,25 $\mathrm{m}$ de comprimento, plantadas verticalmente em covas. Despendeu-se menor tempo no método 4 (18 minutos) pois foram necessárias apenas 30 estacas de 1,0 m de comprimento para serem plantadas horizontalmente, em sulcos por parcela.

O tempo gasto nas operações de plantio diferiu significativamente $(\mathrm{P}<0,01)$ entre os tratamentos pelo teste F. Os menores tempos nas operações de plantio foram gastos nos métodos 4 e 5 (Tabela 4), quando comparados aos outros três pelo teste Tukey $(\mathrm{P}<0,01)$. Esse fato é aceitável, uma vez que as operações de sulcamento do terreno e plantio das estacas, horizontalmente dentro de sulcos, mostraram maior praticidade e rapidez de execução que aquelas com coveamento do terreno e plantio das estacas verticalmente em covas.

O custo para preparação das estacas e operações de plantio diferiu significativamente $(\mathrm{P}<0,01)$ entre os tratamentos pelo teste de F. O método de plantio 4, realizado horizontalmente dentro do sulco (Tabela 4), apresentou o menor custo para preparo das estacas e operações de plantio, enquanto o método 3, o mais elevado.

As estacas de 1,0 m plantadas verticalmente em covas (método 1) apresentaram o maior índice de pegamento (71,67\%), embora, pelo teste Tukey, fossem estatisticamente semelhantes às estacas de $0,5 \mathrm{~m}$ plantadas verticalmente em covas (método 2) e às de $1,0 \mathrm{~m}$ plantadas horizontalmente em sulcos (método 4) (Tabela 5). Estes resultados confirmam aqueles obtidos por Yamoah et al. (1986) que obtiveram melhores resultados com estacas de 1,2 m, quando comparadas às de $0,5 \mathrm{~m}$ em plantios em sulco e em covas.

Neste trabalho, as estacas foram mantidas à sombra por, aproximadamente, 14 dias antes de serem processadas e plantadas, em decorrência de dificuldades de acesso ao local onde foram obtidas. Essa demora no plantio das estacas pode ter ocasionado possível redução no teor de umidade de algumas delas, e, como conseqüência, houve variação em seu índice de pegamento. Essa ocorrência está bem fundamentada nas recomendações de Fact (2003), que sugere o plantio das estacas de gliricídia imediatamente após a colheita, para assegurar bom índice de pegamento, posto que suas gemas podem perder a viabilidade caso as estacas sofram desidratação.

As estacas de $1 \mathrm{~m}$ plantadas verticalmente em covas (método 1) apresentaram a maior produção de matéria seca de folhas (Tabela 5), que foi estatisticamente semelhante à das estacas de 0,5 m plantadas verticalmente em covas (método 2) e das estacas de 0,5 m plantadas horizontalmente em sulcos (Método 5). 
Tabela 4 - Métodos de plantio, tempo gasto na preparação das estacas e nas operações de plantio Table 4 - Planting methods, spending time in stakes preparation and planting operations

\begin{tabular}{|c|c|c|c|}
\hline $\begin{array}{l}\text { Métodos de plantio } \\
\text { Planting methods }\end{array}$ & $\begin{array}{l}\text { Preparação das estacas } \\
\text { (minutos) } \\
\text { Stakes preparation } \\
\text { (minutes) }\end{array}$ & $\begin{array}{l}\text { Operações de plantio } \\
\text { (minutos) } \\
\text { Planting operations } \\
\text { (minutes) }\end{array}$ & $\begin{array}{c}\text { Custo para preparação de estacas e } \\
\text { operações de plantio }\left(\mathrm{R} \$ \mathrm{ha}^{-1}\right) \\
\text { Stakes preparation and } \\
\text { planting operations costs }\end{array}$ \\
\hline $\begin{array}{l}1 \text {-Vertical em covas }-1,0 \mathrm{~m} \\
1 \text { - Vertical in pits }-1.0 \mathrm{~m}\end{array}$ & $35 c$ & $39,4 a$ & $930,00 \mathrm{~d}$ \\
\hline $\begin{array}{l}2 \text { - Vertical em covas - 0,5 m } \\
2 \text { - Vertical in pits }-0.5 \mathrm{~m}\end{array}$ & $40 b$ & 39,6а & $995,00 \mathrm{~b}$ \\
\hline $\begin{array}{l}3 \text { - Vertical em covas }-0,25 \mathrm{~m} \\
3 \text { - Vertical in pits }-0.5 \mathrm{~m}\end{array}$ & $55 a$ & $39,4 a$ & 1180,00 a \\
\hline $\begin{array}{l}4 \text { - Horizontal em sulcos }-1,0 \mathrm{~m} \\
4 \text { - Horizontal in furrows }-1.0 \mathrm{~m}\end{array}$ & $18 d$ & $36,4 b$ & $680,00 \mathrm{e}$ \\
\hline $\begin{array}{l}5 \text { - Horizontal em sulcos }-0,5 \mathrm{~m} \\
5 \text { - Horizontal in furrows }-0.5 \mathrm{~m}\end{array}$ & 40b & $37,6 b$ & $970,00 \mathrm{c}$ \\
\hline DMS & 1,902 & 1,367 & 23,473 \\
\hline CV $(\%)$ & 2,06 & 1,45 & 1,00 \\
\hline
\end{tabular}

Médias seguidas de letras diferentes, na coluna, diferem $(\mathrm{P}<0,01)$ pelo teste Tukey.

Means followed by different letters in the same column are different $(P<.01)$ by Tukey test.

Tabela 5 - Índice de pegamento das estacas e produção de matéria seca de folhas

Table 5 - Stakes sprouting index and leaf dry matter production

\begin{tabular}{|c|c|c|}
\hline $\begin{array}{l}\text { Métodos de plantio } \\
\text { Planting methods }\end{array}$ & $\begin{array}{l}\text { Índice de pegamento das estacas (\%) } \\
\text { Leaf sprouting index }\end{array}$ & $\begin{array}{l}\text { Produção de matéria secadas folhas }\left(\mathrm{kg} \cdot \mathrm{ha}^{-1}\right) \\
\text { Leaf dry matter production }\end{array}$ \\
\hline $\begin{array}{l}1 \text { - Vertical em covas }-1,0 \mathrm{~m} \\
1 \text { - Vertical in pits }-1.0 \mathrm{~m}\end{array}$ & 71,67 a & 1290,91 a \\
\hline $\begin{array}{l}2-\text { Vertical em covas }-0,5 \mathrm{~m} \\
2-\text { Vertical in pits }-0.5 \mathrm{~m}\end{array}$ & 58,33 a & 1209,23 a \\
\hline $\begin{array}{l}3 \text { - Vertical em covas }-0,25 \mathrm{~m} \\
3 \text { - Vertical in pits }-0.25 \mathrm{~m}\end{array}$ & $23,33 c$ & 966,37 b \\
\hline $\begin{array}{l}4 \text { - Horizontal em sulcos }-1,0 \mathrm{~m} \\
4-\text { Horizontal in furrows }-1.0 \mathrm{~m}\end{array}$ & $53,33 \mathrm{ab}$ & 928,47 b \\
\hline $\begin{array}{l}5 \text { - Horizontal em sulcos }-1,0 \mathrm{~m} \\
5 \text { - Horizontal in furrows }-1.0 \mathrm{~m}\end{array}$ & 34,99 bc & $1095,23 \mathrm{ab}$ \\
\hline DMS & 23,329 & 215,696 \\
\hline CV (\%) & 19,66 & 8,00 \\
\hline
\end{tabular}

Médias seguidas de letras diferentes, na coluna, diferem $(P<0,01)$ pelo teste Tukey.

Means followed by different letters in the same column are different $(P<.01)$ by Tukey test.

As frações de caule (estacas) utilizadas neste experimento apresentaram diâmetros de 2 a $6 \mathrm{~cm}$. Esta falta de uniformidade no diâmetro das estacas pode ter influenciado na variação dos índices de pegamento e das produções de matéria seca de folhas. Contreras et al. (1998), trabalhando com estacas de 8, 10, 15 e $20 \mathrm{~cm}$ de comprimento e diâmetros de 5 a $10 \mathrm{~cm}$, verificaram que o diâmetro da estaca tem relação direta com porcentagem de germinação. As estacas de $10 \mathrm{~cm}$ de comprimento com diâmetros entre 5 e $6 \mathrm{~cm}$ apresentaram $90 \%$ de ger- minação, enquanto aquelas com diâmetros maiores de 6,1 cm germinaram 100\%.

Estimando-se o preço do quilograma de matéria seca das folhas de gliricídia em $\mathrm{R} \$ 0,80$, obtém-se uma receita de $\mathrm{R} \$ 1.032,73$ e $\mathrm{R} \$ 742,78$ por hectare para os métodos 1 e 4, respectivamente. Desses valores, abatendo-se o custo da preparação das estacas e das operações de plantio chega-se a um lucro de R $\$ 102,73$ e $\mathrm{R} \$ 62,78$ por hectare para os métodos 1 e 4 , respectivamente. As estimativas de lucro para os demais métodos de plantio de estacas de gliricídia não apresentaram resultados favoráveis. 


\section{Conclusões}

As estacas de 1,0 m de comprimento plantadas verticalmente em covas (método 1 ), as de $0,5 \mathrm{~m}$ plantadas verticalmente em covas (método 2) e as de 1,0 m plantadas horizontalmente dentro de sulcos (método 4) apresentaram os melhores índices de pegamento.

As estacas de 1,0 m de comprimento plantadas verticalmente em covas (método 1), as de $0,5 \mathrm{~m}$ plantadas verticalmente em covas (método 2 ) e as de $0,5 \mathrm{~m}$ plantadas horizontalmente dentro de sulcos (método 5) apresentaram as maiores produções de matéria seca por hectare.

Contudo, o plantio de estacas de 1,0 m de comprimento plantadas verticalmente dentro de covas (método 1) ou horizontalmente dentro de sulcos (método 4), após 14 dias de colhidas, é o método mais recomendável, por apresentar menores custos com a preparação das estacas e as operações de plantio, proporcionando melhores lucros por hectare, quando consideradas as receitas das produções de matéria seca.

\section{Literatura Citada}

BAGGIO, A.J. Possibilidades de Gliricidia sepium para uso em sistemas agroflorestais no Brasil. Pesquisa Agropecuária Brasileira, v.19, sn, p.24-243, 1984.

CAMERO, L.A. Poró (Erythrina poeppigiana) y madero negro (Gliricidia sepium) como suplementos protéicos em la produción de leche. Agroforesteria em las Américas, v.1, n.1, p.6-8, 1994.

CAREW, B.A.R. Gliricídia sepium as sole feed for small ruminants. Tropical Grasslands, v.17, p.181-184, 1983.

CARVALHO FILHO, O.M.; DRUMOND, A.M.; LANGUIDEY, P.H. Gliricidia sepium, leguminosa promissora para região semi-árida. Petrolina: EMBRAPA/CPATSA, 1988. 10p. (Circular, 3)

CONTRERAS, V.E.; BELÉN, E.; DIAZ, C. et al. Porcentagem de estacas de Gliricidia sepium rebrotadas em función de la longititud y el diâmetro, para la siembra automatizada. Parte II. Disponível em: http://www.members.tripod.com/ vcontrer/gliricidia5/proy5.htm Acesso em: 25/12/2002.

FACT net. Gliricidia sepium, the quintessential agroforestry species. Fact Sheet 98-04, june 1998. 4p. Disponível em: $<$ www.winrock.org/forestry/factnet.htm Acesso em: 25/12/2002)
FACT net. Growing Gliricidia. NFT Highlights a quick guide to useful nitrogen fixing trees from around the world, 2003. 3p. Disponível em: < www.winrock.org/forestry/factpub/ FACTSH/Grow_gliricid.html> Acessado em: 10/01/2003

GALINDO, W.F.; ROSALES, M.; MURGUEITIO, E. et al. Sustancias antinutricionales em las hojas de Guano, Nacedero y Matarratón. Livestock Research for Rural Development, v.1, n.1, p.1-10, 1989. On line edition. Disponível em: http://www.cipav.org.co//lrrd> acesso em 16/04/2004.

GÓMEZ, M.E.; RODRIGUEZ, E.; MURGUEITIO, E. et al. Arboles y arbustos forrajeros utilizados en alimentacíon animal como fuente protéica. Cali: CIPAV, 1995. 129p.

LIYANAGE, L.V.K.; WIJERATNE, A.M.U. Uses and management of Gliricidia sepium in coconut plantations of Sri Lanka. In: WITHINGTON, D.; GLOVER, N.; BREWBAKER, J.L. (Eds.). Gliricídia sepium (Jacq.) Walp., management and improvement. Turrialba: NFTA, 1987. p. 95-101 (Special Publication 87-01)

NOCHEBUENA, G.; O’ODONOVAN, P.B. The nutritional value of high protein forage from Gliricidia sepium. World Animal Review, v.57, p.48-49, 1986.

PARROTTA, J. Gliricidia sepium (Jacq.) Walp. Gliricidia, mother of cocoa. SO-ITF-SM-50. New Orleans, LA: U.S. Departament of Agriculture, Forest Service, Southern Forest Experiment Station, 1992. 7p.

QUINTERO DE VALLEJO, V.E. Evaluación de leguminosas arbustivas em la alimentación de conejos. Livestock Research for Rural Development, v.5, n.3, p.1-7, 1993. On line edition. Disponível em: http://www.cipav.org.co//lrrd> Acesso em: 21/04/2000.

RIBEIRO JR., J.I. Análises estatísticas no SAEG. Viçosa, MG: Universidade Federal de Viçosa, 2001. 301 p.

RIBEIRO, L.P.; SANTOS, D.M.B.; LIMA NETO, I.A. et al. Levantamento detalhado dos solos, capacidade de uso e classificação de terras para irrigação da Estação de Plasticultura da Universidade Federal da Bahia/Politeno em Cruz das Almas (BA). Revista Brasileira de Ciência do solo, v.19, n.1, p.105-113, 1995

SILVA, L.F. Comportamento da Gliricidia sepium implantada em solos de tabuleiro no sul da Bahia, 2000. Disponível em: <http: // www.agrobrasil.com.br/agroartigos/artigo/6/ index.htm $>$, Acesso em: 03/09/2000.

SIMONS, A.J.; STEWART, J.L. Gliricidia sepium, a multipurpose forage tree legume. In: GUTTERIDGE, R.C.; SHELTON, H.M. (Eds.) Forage tree legumes in tropical agriculture. Wallinford: CAB International, 1994. p.30-48.

YAMOAH, C.F.; AY, P.; AGBOOLA, A.A. The effects of some methods of establishing Gliricidia sepium on food crop performance, growth and survival rate of Gliricidia. The International Tree Crop Journal, v.4, p.17-31, 1986.

Recebido em: 03/09/03 Aceito em: 24/05/04 